\title{
Aderir ou resistir ao cultivo do tabaco? Histórias de trabalhadores rurais de localidade produtora no Sul do Brasil
}

\author{
Adhering to or resisting tobacco cultivation? \\ Stories of rural workers from a producing region in southern Brazil
}

Deise Lisboa Riquinho ${ }^{1}$

Élida Azevedo Hennington ${ }^{2}$

${ }^{1}$ Curso de Enfermagem, Universidade Federal do Rio Grande do Sul. R. São Manoel 963/220, Rio Branco. 90.620-102 Porto Alegre RS Brasil. deise.riquinho@gmail.com

${ }^{2}$ Instituto Nacional de Infectologia, Fundação Oswaldo Cruz.

\begin{abstract}
This study sought to understand the standpoints of farming families who have resisted or abandoned tobacco cultivation and also the perceptions of State representatives, civil society organizations and the tobacco industry regarding the implementation and the continuity of this cultivation in a producing region in southern Brazil. In this ethnographic study, 27 semi-structured interviews were conducted with farming families and key informants. Besides that, participant observation was conducted. For those who abandoned tobacco cultivation, the main reason mentioned was indebtedness, and for those who have never planted, the main reasons alleged were fear of indebtedness, a limited workforce or religious issues. State representatives and civil society organizations highlighted illusory financial returns as the main reason for tobacco cultivation. Tobacco industry representatives insisted on the difficulty of commercializing the production and the low price of foodstuffs as a stimulus to adhere to the integrated system. It is therefore concluded that the formation of associations and the development of crop rotation plans are important strategies to be adopted to facilitate the change of cultivation in order to promote better working and living conditions for the rural population.

Key words Health of the rural poulation, Tobacco, Public health, Sustainable agriculture, Qualitative research
\end{abstract}

Resumo Este estudo teve o objetivo de compreender as concepções de famílias de agricultores que resistiram ou desistiram do cultivo do tabaco e também as percepções de representantes do Estado, de organizações da sociedade civil e da indústria a respeito da implantação e persistência deste cultivo em localidade produtora no sul do Brasil. Neste estudo do tipo etnográfico foram realizadas 27 entrevistas semiestruturadas com famílias de agricultores e informantes-chave, e ainda observação participante. Para as que desistiram do cultivo, o principal motivo apontado foi o endividamento e para os que nunca plantaram, os principais motivos alegados foram medo do endividamento, limitação da força de trabalho ou questões religiosas. Os representantes do Estado e de organizações da sociedade civil destacaram como motivadores à plantação do tabaco os ganhos monetários ilusórios. Os representantes da indústria apoiaram-se na dificuldade de comercialização e baixo preço dos produtos alimentares como estímulo para adesão ao sistema integrado. Conclui-se que o estímulo ao associativismo e o planejamento de cultivos rotativos são estratégias importantes a serem adotadas para favorecer a mudança do cultivo de modo a refletir em melhores condições de vida e trabalho da população rural.

Palavras-chave Saúde da população rural, Tabaco, Saúde pública, Agricultura sustentável, Pesquisa qualitativa 


\section{Introdução}

A migração do cultivo do fumo dos países desenvolvidos (Estados Unidos da América, países da União Europeia e Japão) para os em desenvolvimento como o Brasil e alguns países africanos como o Malawi é um fenômeno favorecido por um conjunto de ações dos governos daqueles países como a diminuição do subsídio ao plantio, maior número de ações de controle ao tabagismo, o aumento nos custos de produção e declínio na lucratividade ${ }^{1}$.

A migração da produção do tabaco para os países em desenvolvimento no contexto do capitalismo mundial, operacionalizado pela transnacionalização do capital e de seu sistema produtivo é uma estratégia da indústria, tendo em vista a manutenção e o fortalecimento do oligopólio favorecido por políticas econômicas, ambientais e trabalhistas frágeis. Em relação à força de trabalho, observa-se que os agricultores que cultivam tabaco nesses países geralmente são pobres, têm acesso limitado à informação das consequências do cultivo para a sua saúde e de suas famílias, bem como das alternativas de produção economicamente viáveis ${ }^{2,3}$.

Criado pela British American Tobacco, uma acionária da Souza Cruz, o sistema integrado foi implantado no Brasil em Santa Cruz do Sul no início do século passado, expandindo-se e consolidando-se na região sul do Brasil em meados dos anos 1980. No sistema integrado há o compromisso legal entre as partes, produtor e indústria, de produção e compra, fornecimento de assistência técnica e insumos. Como consequência deste sistema as empresas passaram a dominar e controlar todas as fases da produção. Na presença de débitos, as empresas operam na classificação do fumo, aumentando assim, a dívida a cada ano e impedindo ou dificultando a interrupção de tal cultivo ${ }^{4}$.

Levando-se em conta a condição de vulnerabilidade desses agricultores, a adesão à fumicultura caracteriza-se muito mais como uma condição imposta do que uma escolha deliberada. Ao considerar a noção de desenvolvimento de Amartya $\operatorname{Sen}^{5}$ a qual consiste na eliminação da privação da liberdade que limita as escolhas e as oportunidades das pessoas para exercerem sua condição de agente, interroga-se quem são as famílias agricultoras de região produtora de fumo e qual o grau de liberdade que têm para fazerem escolhas sobre o tipo de cultivo.

Este artigo apresenta resultados de pesquisa cujo objetivo foi compreender as concepções dos agricultores que resistiram ou desistiram do cul- tivo do tabaco, sobre a não adesão e/ou a substituição do cultivo, e ainda revelar as percepções de outros atores relevantes, representantes do Estado, de organizações da sociedade civil e da indústria do tabaco em relação à implantação e persistência deste cultivo em localidade rural de região produtora no sul do Brasil.

\section{Percurso metodológico}

Foi desenvolvido estudo qualitativo do tipo etnográfico em uma localidade rural produtora de tabaco no interior do RS. Segundo Geertz ${ }^{6}$ a descrição etnográfica é interpretativa e o que ela interpreta é o fluxo do discurso social, fixando o "dito" em formas pesquisáveis numa descrição microscópica. Apesar de microscópica, esta descrição não deve perder contato com as realidades estratificadoras políticas, econômicas e de poder ${ }^{6,7}$. Para conhecê-las é preciso "mergulhar" na estrutura compreensiva e significativa da ação social, na qual a visão de mundo dos diferentes atores e as regras dessas interações não podem ser antecipadas.

Os sujeitos de pesquisa foram 16 famílias de agricultores que desistiram da plantação do tabaco ou que nunca o produziram. Buscou-se contemplar a heterogeneidade social do local: diferentes arranjos familiares e famílias que tinham entre seus membros crianças em idade escolar, diferentes etnias e credos. Para melhor compreender as percepções e ações relativas às transformações nos modos de vida da localidade outros atores fizeram parte do estudo: representantes do Estado, de organizações da sociedade civil e da indústria do tabaco (Quadro 1), totalizando 27 entrevistas. A amostra estudada foi intencional e os entrevistados foram indicados por informantes-chave da comunidade.

O principal arranjo familiar na localidade foi a família nuclear. Quase a totalidade dos agricultores se identificava como "brasileiro", apenas um como "pomerano". Para a religião referida houve equilíbrio entre ser católico e ser protestante. A idade dos agricultores entrevistados variou entre 30 a 70 anos com maior concentração etária na faixa dos 30 aos 50 anos. Metade das famílias tinha entre seus membros pessoas aposentadas. A média de integrantes das famílias foi de 3,7 pessoas. A estrutura fundiária das propriedades era de 0,5 a 12 hectares e havia duas famílias com 23 e 50 hectares; a média ficou em 8 hectares de terra. A maioria dos pais possuía o ensino fundamental incompleto e os filhos em idade escolar frequentavam a escola. 
Quadro 1. Caracterização dos entrevistados: representantes do Estado, de organizações da sociedade civil e da indústria

\begin{tabular}{|c|c|c|c|}
\hline \multicolumn{4}{|c|}{ Representantes do Estado - Setor Saúde e Agricultura } \\
\hline Órgão & Profissão & Atividade Principal & Idade (anos) \\
\hline Secretaria Municipal da Saúde & Médico & $\begin{array}{l}\text { Trabalha há } 16 \text { anos no município } \\
\text { atendendo nas localidades rurais, } \\
\text { quinzenalmente. }\end{array}$ & 50 \\
\hline $\begin{array}{l}\text { Associação Riograndense } \\
\text { de Empreendimentos de } \\
\text { Assistência Técnica e Extensão } \\
\text { Rural (Emater/RS) }\end{array}$ & Técnico agrícola & Extensionista Rural 1 & 39 \\
\hline Emater/RS & Agrônomo & Extensionista Rural 2 & 53 \\
\hline $\begin{array}{l}\text { Empresa Brasileira de Pesquisa } \\
\text { Agropecuária (Embrapa) }\end{array}$ & Agrônomo & Pesquisas para a agricultura familiar & 52 \\
\hline \multicolumn{4}{|c|}{ Representantes de Organizações da Sociedade } \\
\hline Órgão & Profissão & Atividade Principal & Idade (anos) \\
\hline $\begin{array}{l}\text { Sindicato dos Trabalhadores } \\
\text { Rurais (STR) }\end{array}$ & Agricultor & Participa do programa do crédito fundiário & 49 \\
\hline STR & Agricultor & Participa do programa do crédito fundiário & 59 \\
\hline $\begin{array}{l}\text { Centro de Apoio ao Pequeno } \\
\text { Agricultor (CAPA) }\end{array}$ & $\begin{array}{l}\text { Técnico em } \\
\text { enfermagem }\end{array}$ & $\begin{array}{l}\text { Desenvolve ações de educação e saúde } \\
\text { junto aos agricultores }\end{array}$ & 46 \\
\hline $\begin{array}{l}\text { União das Associações } \\
\text { Comunitárias (UAC) }\end{array}$ & Técnico agrícola & $\begin{array}{l}\text { Estimula a produção agroecológica e o } \\
\text { cooperativismo }\end{array}$ & 31 \\
\hline $\begin{array}{l}\text { Associação Comunitária Local } \\
\text { (ACL) }\end{array}$ & Agricultor & Presidente da associação & 36 \\
\hline \multicolumn{4}{|c|}{ Representantes da indústria } \\
\hline Órgão & Profissão & Atividade Principal & Idade (anos) \\
\hline Indústria 1 & $\begin{array}{l}\text { Técnico em } \\
\text { contabilidade }\end{array}$ & $\begin{array}{l}\text { Instrutor da indústria } 1 \text {. Responsável } \\
\text { pela captação dos agricultores no início } \\
\text { do plantio e acompanhamento da } \\
\text { atividade, como pedidos de insumos e } \\
\text { comercialização. }\end{array}$ & 31 \\
\hline Indústria 2 & Técnico agrícola & Instrutor da indústria 2 . Idem ao primeiro. & 30 \\
\hline Indústria 3 & Técnico agrícola & Instrutor da indústria 3 . Idem ao primeiro. & 50 \\
\hline
\end{tabular}

Fonte: Riquinho e Hennington8.

Em relação às famílias que plantavam fumo, as características descritas são muito semelhantes com diferença em relação ao tamanho das propriedades: as das famílias produtoras de tabaco eram maiores comparadas com as daqueles que não pro- duziam tabaco. Tais famílias possuíam um número de integrantes um pouco maior, assim como havia maior presença de agricultores aposentados.

A observação participante ocorreu com cinco das 23 famílias produtoras de fumo da localidade 
durante 90 dias de trabalho de campo, de dezembro a agosto de 2011. A escolha desse período se justificou por oportunizar o acompanhamento de um ciclo de trabalho no cultivo do tabaco, do plantio à classificação do fumo.

O tratamento do material produzido a partir das entrevistas e da observação ocorreu por meio de categorização temática9. O estar com os participantes da pesquisa, observar seus modos de vida, bem como a relação com eles estabelecida repercutiram decisivamente no material analisado. Para Geertz ${ }^{10}$ a análise na pesquisa qualitativa é uma modalidade de experiência moral à medida que emerge de um contato direto com os detalhes do cotidiano, afetando a sensibilidade de quem a realiza. Considera-se que as concepções, assim com as visões de mundo vinculam-se à subjetividade, referindo-se a construções sociais para explicar fenômenos e processos a partir das experiências vividas ${ }^{6,7}$.

O projeto de pesquisa foi submetido e aprovado pelo Comitê de Ética em Pesquisa da Escola Nacional de Saúde Pública Sergio Arouca.

\section{Resultados e Discussão}

Os resultados serão apresentados a partir de três categorias principais que resultaram nos seguintes subtítulos: "Histórias de vida e da produção agrícola: onde um começa e o outro finda?"; "O cultivo do fumo e as mudanças na paisagem e nos hábitos de vida" e "Aderir ou resistir? Aspectos econômicos e sociais do cultivo do tabaco e as transformações do viver rural". Procurou-se reconstituir o histórico de vida e trabalho dos agricultores da localidade buscando-se compreender os aspectos que levaram essa comunidade ao cultivo do fumo e ainda os motivos de resistência ou desistência deste por parte de famílias agricultoras. Outros atores foram entrevistados sobre o tema revelando-se seu posicionamento em relação à persistência do cultivo na região.

\section{Histórias de vida e da produção agrícola: onde um começa e o outro finda?}

O município pesquisado caracteriza-se por uma situação agrária de minifúndio e da maioria da população $(63 \%)$ vivendo em área rural ${ }^{11}$. Segundo o representante da UAC, aproximadamente $85 \%$ das propriedades do município atualmente mantêm plantação de tabaco. Na localidade pesquisada, a estrutura fundiária variou de 0.5 a 50 hectares. A estrutura produtiva é típica de agricultura familiar e com predomínio do uso da força de tração animal. Historicamente, o policultivo de feijão, milho, amendoim, ervilha e soja destinava-se à subsistência e à comercialização de excedentes.

O início do cultivo voltado à comercialização atrelada à indústria ocorreu com o plantio de pêssego na década de 1970. Com o passar do tempo este produto não se mostrou mais rentável; o preço pago pela indústria, segundo os agricultores, não cobria os investimentos na lavoura. Esse período foi marcado pelo calote da indústria e parcelamento de dívidas. A partir de 1990 iniciou-se o plantio do tabaco na localidade. Para além das questões econômicas, havia um clima de confiança em relação à indústria fumageira, pois esta gozava de prestígio junto à comunidade por diversas ações sociais realizadas na escola local como o Clube da Árvore e também pelo apoio institucional a eventos e campanhas promovidos pelo poder público municipal.

Agricultores relembraram que há cerca de 60 anos atrás, na época de chegada das famílias à localidade, era preciso o corte de árvores do mato nativo em beira de córrego para troca por mercadorias em algum comércio local. As árvores cortadas eram transformadas em "acha" (lenha) e em aproximadamente uma semana precisavam ir novamente à busca de outras árvores para o corte nos intervalos do trabalho da lavoura e assim reabastecer a casa de alimentos. Nessa época, o trabalho na lavoura não era suficiente para suprir as necessidades da família.

Para comercializar o excedente da produção e a "acha" na cidade, as famílias de agricultores utilizavam o carro de boi, chegando a vender seus produtos em municípios mais distantes. Posteriormente, houve o desenvolvimento de plantação de soja que se destinava à comercialização. Esse plantio aos poucos foi deixando de ser uma atividade produtiva na localidade pesquisada. Para um dos entrevistados o principal motivo foram dificuldades para aumentar a produção e comercialização do produto: o pequeno agricultor plantava a soja e colhia manualmente; já o grande mantém o cultivo com maquinário, plantando grandes extensões e tendo mais poder para negociar com os mercados (Família 1).

Outra atividade por eles lembrada era o trabalho temporário em lavouras para cortar arroz manualmente. Famílias inteiras mudavam-se por um período de um a três meses e quem ficava na localidade era responsável, mediante algum pagamento, por cuidar dos animais de quem havia ido para as lavouras de arroz. Permaneciam na 
localidade pessoas com algum problema de saúde e algumas mulheres. As crianças, especialmente os filhos, acompanhavam os pais neste trabalho e, segundo eles, chegavam a faltar cerca de dois meses de aula, naquela época [criança] faltava ao colégio pra trabalhar (Família 15). As crianças tinham dez, doze anos e trabalhavam juntos com os pais e não recebiam pagamento pelo seu trabalho.

Mais tarde predominou a colheita do pêssego na localidade estudada. Os agricultores relembraram a chegada da indústria: a abertura de vagas extras para o seu beneficiamento; os ônibus que buscavam os trabalhadores para o trabalho e também que todos recebiam regularmente por suas atividades. $O$ trabalho infantil era utilizado temporariamente pelas empresas que processavam pêssegos. Uma das entrevistadas ao relembrar esta época, recorda o conselho recebido de seu pai sobre o trabalho na agricultura e a relação com a indústria: filha, tu sabendo trabalhar e respeitar, tu estás com tudo (Família 5). Tais palavras apontam para o valor e a centralidade do trabalho na vida do trabalhador rural aliado a uma postura de subserviência ao controle da produção imposto pela indústria.

Nos relatos o trabalho aparece para este grupo de agricultores muitas vezes associado ao adoecimento. Para alguns dos agricultores entrevistados o início precoce no trabalho, no corte da soja, colhendo cebola ou pêssego, influenciou nos adoecimentos da vida adulta: a gente se criou sempre debaixo do serviço forçado, então por isso hoje a gente não tem mais saúde (Família 15).

Os principais problemas de saúde referidos pelos entrevistados foram os osteomusculares caracterizados por dor ou "problema na coluna" e ainda em membros superiores e inferiores, sendo relatado tanto por jovens quanto por pessoas com mais idade. Segundo eles, a postura no trabalho contribui para estes problemas: eu trabalhava muito agachado (Família 6). Mas apesar da dor, os entrevistados mantinham suas atividades domésticas e de trabalho. Os relatos resignados com a situação revelam que os de mais idade diminuíram o ritmo de trabalho, especialmente quando aposentados: os meus braços e ombros tão estragados, então a gente tem que fazer as coisinhas mais leves porque o corpo não dá mais (Família 15).

As transformações nessa localidade não dizem respeito apenas ao tempo biográfico e ao adoecimento como consequência do trabalho. Um marco significativo relembrado pelos agricultores foi o início e disseminação do cultivo do fumo: como deu essa queda no pêssego, o povo se desesperou e as fumageiras entraram na hora certa, o povo tava meio carente e a propaganda deles é boa, e é enganosa (presidente da ACL). A falta de perspectivas com outros cultivos e a propaganda positiva desse plantio levaram muitos dos agricultores a aderirem ao sistema integrado do tabaco.

\section{O cultivo do fumo e as mudanças na paisagem e nos hábitos de vida}

Os agricultores que não plantavam fumo reconheceram que o plantio aumentou nos últimos cinco anos. A paisagem da localidade se modificou. Ao olharem as "coxilhas", avistam as lavouras de fumo substituindo plantações de feijão, milho ou batata. Os alimentos que antes eram produzidos nas pequenas propriedades e a plantação de uma uma horta, tá tudo terminado, só juntam o dinheiro do fumo, e aí vão ao supermercado buscar (Família 4). Para esta família não é compreensível: como algo que não sirva para a sobrevivência das pessoas como o fumo tenha maior valor monetário que o alimento? A folha de fumo ninguém come e já um pêssego, um cacho de uva, enfim, o que tem valor, eles deixam cair lá em baixo. Vai terminar o alimento porque sem fumo todo mundo vive, mas (sem) alimento não (Família 4).

Uma das mudanças evidenciadas na localidade estudada e testemunhada por outros atores, como o representante da Embrapa, é em relação ao declínio do cultivo para subsistência. No meio rural agora têm caminhões vendendo verdura, leite e até pão. Para este informante, o êxito do pequeno agricultor vem da agricultura familiar, pelo seu cultivo diversificado, alternando a plantação e assim tendo alimento e renda durante o ano inteiro. Um dos diferenciais entre o cultivo do pêssego e do fumo é que o primeiro permitia que os agricultores cultivassem outros produtos, pois a rotina de trabalho não era tão intensa, nem a cobrança da indústria, como acontece com o tabaco, salientou o entrevistado da Família 15.

Na visão do médico entrevistado, as mudanças na localidade, caracterizada anteriormente pelo cultivo para subsistência, venda de excedentes e plantação do pêssego, e a passagem para o plantio do fumo refletem as transformações sociais e a busca do ser humano pela melhoria das condições de vida. Trata-se de uma questão de geração e das mudanças dos tempos, das realidades e da percepção da realidade pelos agricultores, aliado ao apelo da indústria do fumo que os convence dos benefícios e lucratividade desse plantio (Médico).

Poucos agricultores se mantiveram no cultivo do pêssego: dos entrevistados, foram sete famílias e, destas, duas fazem parte de uma associação 
fundada há 25 anos em uma localidade vizinha que trabalha na comercialização e beneficiamento de pêssego. Outro agricultor negocia direto com a indústria por produzir um volume maior de frutas e os demais comercializam em feiras na cidade ou ainda com a indústria. Para a Família 14 , o preço pago pela associação valorizou o pêssego - o valor superou o da indústria. No entanto, ressaltou as dificuldades em manter processos associativos na localidade: aqui nada dá certo, as pessoas falam muito uma das outras, são muito desconfiadas.

Apesar das dificuldades de união dos trabalhadores algumas iniciativas são mantidas, como referiu um dos agricultores entrevistados, que além de participar da associação citada anteriormente, também destina sua produção a feiras ecológicas. Há quase 20 anos um grupo de agricultores com orientação de técnicos agrícolas mantidos pela igreja católica e luterana iniciaram este processo de agroecologia com perspectiva de um mercado direito ao consumidor, sem intermediários.

Para os agricultores que trabalham de forma isolada ou que ainda não estabeleceram um canal direito com o consumidor, a lei do mercado de oferta e demanda precisa ser equacionada. Em relação às dificuldades de comercialização dos produtos por parte do pequeno agricultor, uma das trabalhadoras relatou: temendo a queda de geada, colheram espigas de milho verde e foram vender na cidade em um supermercado juntamente com amendoim e batata doce. Em duas semanas ganharam o equivalente a um salário mínimo (Família 1). Estes ganhos são esporádicos, mas revelam o potencial e os desafios na produção e comercialização para os pequenos produtores.

Algumas famílias de agricultores que não cultivam tabaco trabalham como diaristas nas diversas etapas do cultivo, mas principalmente na colheita, que demanda maior concentração e exigência de força de trabalho. Uma agricultora conta como é sua rotina de trabalho e compara a colheita do tabaco com a do pêssego: a gente pega às oito da manhã e solta às nove da noite, a diferença é, o fumo é assim, um serviço leviano (levinho), ele não é pesado, é cansativo, mas não é pesado. Já numa chácara de pêssego às vezes a distância é longe para carregar os balaios e o pessegueiro alto (Família 10). Esta fala de certo modo contradiz outras que referem a necessidade de um esforço e tempo muito maior no cultivo do tabaco em suas várias etapas e do desgaste decorrente disto.

Outra forma de trabalho na localidade é no corte de lenha "metro", como os agricultores denominam a de eucalipto. Em época de cura do tabaco, o uso de lenha é muito requisitado e os cortadores ganham uma percentagem do que é comercializado. Em frente às estufas ficam muitos cortes de eucalipto. Uma das agricultoras que não planta mais tabaco reconhece que essa prática é uma maneira de demonstrar à fiscalização do Instituto Brasileiro do Meio Ambiente e dos Recursos Naturais Renováveis (IBAMA) a procedência da lenha, mas ainda se utiliza mato nativo. Os custos do metro para cura do tabaco são responsáveis por boa parte dos custos do cultivo e processamento ${ }^{12}$.

As famílias que não estão envolvidas com a produção de tabaco salientam que o plantio do fumo causa desgaste à saúde e que o dinheiro adquirido não compensa o adoecimento decorrente. Explicam que os agricultores que trabalham com o tabaco conhecem as determinações das empresas fumageiras quanto ao uso de roupas específicas - equipamento de proteção individual - para cada etapa do trabalho, mas tal exigência não é cumprida, assim como a não utilização da força de trabalho infantil e de pessoas acima de 60 anos de idade. Usar todo o equipamento de proteção na aplicação de agrotóxico ou na colheita é dificultado pelas altas temperaturas do verão aliado ao entendimento de que tais vestimentas atrapalham mais que ajudam no trabalho ${ }^{8,13}$.

O trabalho infantil como se pode observar pelo histórico do local é algo naturalizado. Atualmente, com as políticas redistributivas do governo federal às famílias de baixa renda, como para aquelas com crianças que frequentam escola e a divulgação nas mídias dos prejuízos do trabalho infantil, as famílias têm mantido seus filhos na escola, porém no turno inverso e em férias escolares elas ainda trabalham. Em relação aos idosos, suas relações sociais foram forjadas a partir do trabalho, sendo este um elo com "o mundo vivido". Apesar das limitações físicas, o trabalho faz parte de sua rotina; apenas com a aposentadoria e sérias limitações físicas eles diminuem o trabalho na lavoura.

A Família 1 argumenta: só quem entra numa estufa quando estão carregando e descarregando [fumo seco] é que sente o que está aí. Eu trabalhei algum tempo, faz uns cinco anos. Aquela poeira, quando tá carregando, aquele cheiro, só aguenta quem tá lá trabalhando mesmo. Observam ainda que até a qualidade do ar está diferente, especialmente nos meses de cura do tabaco, de dezembro a março; a fumaça impregna o ar e nas casas próximas e as pessoas queixam-se de ardência no nariz (Famílias 1, 4 e 5).

Duas famílias entrevistadas afirmaram que o principal motivo de não plantar fumo vem da sua 


\section{Aderir ou resistir? Aspectos econômicos e sociais do cultivo do tabaco e as transformações do viver rural}

Uma das famílias que ao cultivar tabaco não obteve lucros, mas endividamento, assinalou que apesar dos conselhos de amigos que alertavam para as dificuldades do plantio, eles resolveram arriscar. As dívidas com a indústria se estenderam ao armazém onde compravam alimentos e também acabaram sem crédito. Reconheceram que pelo trabalho que o cultivo de fumo exige, não há retorno financeiro. Para eles, desde que o agricultor inicia o cultivo, quando semeia, é preciso ficar sempre monitorando seu crescimento ou surgimento de pragas. Descansar e passear com a família deve ser preterido; o plantio do fumo passa a ser o centro da vida social. E pode ocorrer que mesmo tendo feito tudo correto, colhendo um bom fumo, no processo de cura algum equívoco acontece: prende umidade na estufa, muito calor rapidamente ou pouco calor e perde-se a qualidade do fumo e, consequentemente, cai o preço pago pela indústria (Família 7).

Outra família referiu que plantaram fumo por quatro anos e como não obtinham lucro pararam. Relataram que há uma ilusão em relação aos valores obtidos no plantio do fumo: os valores que são declarados se referem ao bruto. Por exemplo, numa safra foram declarados no talão do modelo 15 , quarenta mil reais, mas de lucro não obtiveram dez mil. O talão do modelo 15 tem o propósito de documentar a produção comercializada para geração de receita, impostos e comprovante da atividade de agricultor. Em consequência da renda bruta, no período em que plantaram, o pagamento da bolsa-escola e da bolsa-família foi suspenso. Encerraram o plantio de fumo com dívida, a qual foi quitada com o trabalho de diarista e a venda de animais.

Para os informantes-chave do setor da agricultura, Emater e Embrapa, o envolvimento da força de trabalho familiar muitas vezes é desconsiderado: os agricultores não consideram é que toda aquela renda do fumo eles têm que dividir por três, quatro pessoas; eles não fazem a conta do tempo que eles trabalham no fumo (Extensionista Rural 1). Enfatizaram, ainda, a questão de que o fumo demanda trabalho o ano inteiro. Quando termina uma safra, já começam a fazer as mudas, as aplicações de agrotóxicos nas diferentes etapas do plantio. Após a colheita vem a secagem e a seguir a classificação para finalmente comercializar. Esse processo mantém as famílias ininterruptamente ocupadas durante os 12 meses e, às vezes, as etapas do cultivo se sobrepõem como ao fazer o semeio da safra seguinte e a classificação das folhas da anterior, fazendo-se muitas vezes necessária a contratação de força de trabalho externa ao meio familiar.

Um dos extensionistas da Emater complementa que em certas propriedades não se tem a produção esperada porque o solo está muito degradado: os agricultores sofrem, passam muito trabalho plantando uma área grande e não têm a produção esperada; eles têm que pagar muitas vezes para terceiro, para pode cumprir aquela etapa toda, e no fim não tem o resultado esperado na produção (Extensionista Rural 1).

Uma terceira família que desistiu de plantar fumo contou que durante os três anos que cultivaram tabaco obtiveram um pequeno lucro. $\mathrm{O}$ primeiro ano foi quando menos plantaram e quando maiores lucros atingiram. Na medida em que aumentou o número de pés de fumo, diminuiu o lucro. Diferentemente, relataram que seu filho desde o primeiro ano não conseguiu ter lucro na plantação. Ele demonstrou sua insatisfação em relação às orientações recebidas para os cuidados na plantação: a capina manual, por exemplo, não é recomendada, apenas a química.

Ao recordar as condições de vida na localidade, um dos entrevistados, antigo morador, que viveu diferentes ciclos de plantação como o da ervilha, da soja, do pêssego e, mais recentemente, do fumo, observou que o poder de compra com crédito facilitado alterou os modos de vida dos agricultores. Praticamente todas as famílias têm moto. Além disso, os benefícios que o governo tem dispensado ao povo ajudou muito (Família 11). Para ele, a aposentadoria tem garantido um aporte financeiro ao meio rural e evitado a fome. Os produtos cultivados como feijão, cebola e milho não têm valor comercial suficiente para garantir a compra de outros produtos alimentícios ou mesmo o pagamento de certas comodidades da vida moderna, como telefone e luz (Instrutor 1).

Outra entrevistada apontou as mudanças advindas com a aposentadoria: mencionou que sempre trabalhou de peão e que plantavam uma 
lavourinha para subsistência como meeiro (Família 10). Outras famílias mencionaram a expectativa em chegar à aposentadoria; o trabalho na agricultura de maneira geral garante a sobrevivência e a aposentadoria permite certa qualidade de vida, acesso a compras e crédito. A bolsa-escola também foi mencionada como um facilitador, auxiliando na compra de material escolar e uniformes para os escolares. Da mesma forma, o Programa Nacional de Fortalecimento da Agricultura Familiar (PRONAF) e o crédito para melhoramento do gado leiteiro contribuíram para melhorar a qualidade da vida no campo.

O Pronaf é um programa de crédito para a agricultura familiar brasileira, que começou em 1995, incentivando a produção e a melhoria da infraestrutura no meio rural, por meio de diferentes linhas de crédito, como as relacionadas ao gado de leiteiro, e pela aquisição de alimentos com juros baixos e subsidiados ${ }^{14}$.

A aposentadoria rural e o benefício em situação de doença passam a constituir-se um direito pleno, universalizado para toda a população; homens e mulheres tiveram igualdade de acesso a partir da Constituição de $1988^{15}$. A aposentadoria rural representa atualmente a principal política de enfrentamento à pobreza no campo, atendendo a 7,8 milhões de trabalhadores rurais ${ }^{16}$.

Juntamente com a aposentadoria rural os programas de transferência de renda passaram a constituir o eixo central da proteção social no Brasil para o enfrentamento da pobreza ${ }^{16}$. O Bolsa Família, criado no ano de 2003, é considerado o maior programa de transferência de renda no país, com implementação descentralizada em todos os municípios ${ }^{16}$. De acordo com Senna et al. ${ }^{17}$, é preciso considerar que a perspectiva de inclusão social do Bolsa Família também está ancorada na oferta de programas complementares, como geração de emprego e renda, cursos profissionalizantes, microcrédito, compra da produção agrícola e apoio a iniciativas da economia solidária, entre outros. E, assim, tornar as famílias menos dependentes de programas de transferência de renda e mais protagonistas de seus processos de vida e trabalho ${ }^{18}$.

As dificuldades de participação em discussões e em redes associativistas é um forte limitador de iniciativas que tenham sua centralidade nos âmbitos exclusivamente locais, pois o Estado possui uma longa história de planejamento centralizador ${ }^{19}$. Assim, as ações participativas precisam ser estimuladas, como por exemplo, oportunizando discussões em cada localidade, para que os agricultores possam se apropriar dos objetivos desses recursos, e assim o utilizarem de forma a fomentar o desenvolvimento rural sustentável, cujas premissas incluem noções de equidade social, além da incorporação de novas tecnologias que permitam o aumento da produção e da produtividade e, desse modo, da renda familiar ${ }^{19}$.

\section{Considerações finais}

Ao buscar entender as concepções dos agricultores que resistiram ou desistiram do cultivo de tabaco na localidade estudada, em que a grande maioria das famílias agricultoras optou pelo sistema integrado, compreende-se que são múltiplos os sentidos que compõem essas decisões. Primeiramente na caracterização destas famílias: observa-se que entre seus membros existiam pessoas com aposentadoria rural e que apesar de serem um pouco mais numerosas em relação às que cultivam tabaco, possuem menos hectares de terra. A aposentadoria que garante alguma renda e a pouca extensão de terra parecem influenciar a decisão pelo não cultivo, aliado ao receio de endividamento na compra de terra e a necessidade de força de trabalho mais jovem e hígida. Os integrantes mais jovens das famílias e que possuem condições para o trabalho o fazem como diaristas nas lavouras de tabaco ou ainda no corte de madeira. Questões de coerência religiosa aparecem como um fator de menor influência decisória, porém presente no discurso de duas famílias.

Para as famílias que desistiram do cultivo, o principal motivo apontado foi o endividamento. $\mathrm{O}$ êxito financeiro esperado e prometido pela indústria foi frustrado mediante sucessivas tentativas. Apesar da grande dedicação de tempo e cuidados nas diferentes etapas de trabalho, não obtiveram os ganhos esperados e ainda acabaram devedores do banco e da indústria.

Os representantes do Estado destacaram, assim como alguns agricultores, as mudanças no cultivo de subsistência que diminuíram para o plantio do tabaco. Ao comprar estes produtos no comércio local os agricultores estão perdendo a aptidão para o policultivo e, possivelmente, também estará baixando a qualidade dos alimentos que vão à mesa. Os representantes do Estado $\mathrm{e}$ de organizações da sociedade civil ainda chamam a atenção para a degradação do solo e os ganhos monetários ilusórios. Neste caso, se movimenta um montante de dinheiro robusto, mas as famílias ficam com menos da terça parte. Os argumentos dos representantes da indústria se baseiam na dificuldade de comercialização e no 
baixo preço dos produtos alimentares alternativos, como o feijão e o milho, para propagar as vantagens do cultivo do tabaco.

O trabalho foi evidenciado como algo que constitui a identidade social do trabalhador rural. E o trabalho infantil é tido como natural neste meio, mas também como algo que gera adoecimento de crianças e adolescentes, incapacitando -os para desenvolver plenamente suas aptidões e demais atividades ao longo da vida. Sabidamente o trabalho infantil limita as potencialidades de estudar, de apreender outras experiências e pode afetar o desenvolvimento físico e cognitivo dos sujeitos, perpetuando iniquidades sociais e de saúde.

O passado vivido de pobreza, com pouca terra, trabalhando como meeiro, ou seja, lavrando, cultivando e destinando um terço da produção ao dono da terra, o adoecimento e ainda a utilização da força de trabalho infantil para dar conta das tarefas e compromissos continua no presente. $\mathrm{Na}$ atualidade, "o dono da terra" passou a ser a indústria do tabaco e para esta se destina um terço do que é produzido. Como romper com esse ciclo de exploração, subserviência, adoecimento e pobreza? As políticas sociais como a aposentadoria rural e o PRONAF e, ainda, as políticas redistributivas como o Bolsa Família significaram melhorias nas condições de vida e consumo de bens que estavam fora do alcance da maioria da população rural. Especialmente em relação ao Bolsa Família se faz necessário maior investimento do município que cadastra as famílias e a elas destina os recursos em uma atuação integrada de diferentes órgãos e setores do governo como o Ministério de Desenvolvimento Agrário, Embrapa e Emater no sentido de empoderar a população rural para que consiga superar as dificuldades impostas pelo modelo hegemônico capitalista personificado nessa localidade pelo sistema integrado de produção do tabaco. O estímulo ao associativismo nos moldes dos projetos da economia solidária, a diversificação agrícola por meio do planejamento de um cultivo rotativo que garanta renda o ano inteiro e a produção de valor agregado, com garantia de comercialização através de parcerias e do consumo local, seriam estratégias importantes a serem fomentadas.

\section{Colaboradores}

DL Riquinho trabalhou no desenvolvimento da pesquisa, na metodologia, na concepção do artigo e na escrita final; EA Hennington participou de todas as etapas do trabalho orientando e revisando o artigo. 


\section{Referências}

1. Kingsolver AE. Farmers and Farmworkers: two Centuries of Strategic Alterity in Kentucky's Tobacco Fields. Critique of Anthropology 2007; 27(1):88-102.

2. Arcury TA, Quandt SA. Health and social impacts of tobacco production. J Agromedicine 2006; 11(3-4):7181.

3. Otanãez MG, Mamudu HM, Glantz SA. Tobacco companies' use of developing countries' economic reliance on tobacco to lobby against global tobacco control: the case of Malawi. Am J Public Health 2009; 99(10):17591771.

4. Previtalli FS, Faria AF. Reestruturação produtiva e controle do trabalho o caso do setor de tabaco em Uberlândia/MG. Antítese 2008; 1(1):95-117.

5. Sen A. Desigualdade reexaminada. Rio de Janeiro: Record; 2001.

6. Geertz C. A Interpretação das culturas. Rio de Janeiro: LTC; 2008.

7. Velho G. Observando o familiar. In: Nunes EO, organizador. A aventura sociológica: objetividade, paixão, improviso e método na pesquisa social. Rio de Janeiro: Zahar; 1978. p. 36-46.

8. Riquinho DLR, Hennington EA. Health, environment and working conditions in tobacco cultivation: a review of the literature. Cien Saude Colet 2011; 17(6): 1587-1600.

9. Minayo MCS. O desafio do conhecimento. $10^{\text {a }}$ ed. São Paulo: Hucitec; 2007.

10. Geertz C. Nova luz sobre a antropologia. Rio de Janeiro: Jorge Zahar Editor; 2001.

11. Instituto Brasileiro de Geografia e Estatística (IBGE). Cidades. Rio de Janeiro: IBGE; 2010. [acessado $2012 \mathrm{mar}$ 15]. Disponível em: http://www.ibge.gov.br/cidadesat/ topwindow.htm? 1

12. Lecours N, Almeida GEG, Abdallah JM, Novotny TE. Environmental health impacts of tobacco farming: a review of the literature. Tobacco Control 2012; 21(2):191-196.
13. Riquinho DLR, Hennington EA. Cultivo do tabaco no sul do Brasil: doença da folha verde e outros agravos à saúde. Cien Saude Colet. No prelo 2014.

14. Brasil. Ações do Ministério do Desenvolvimento Agrário para a diversificação da produção e renda em áreas cultivadas com tabaco no Brasil. Brasília: Ministério do Desenvolvimento Agrário; 2010.

15. Instituto de Pesquisa Econômica Aplicada (IPEA). Políticas sociais: acompanhamento e análise. Brasília: IPEA; 2008.

16. Silva E, Silva MO. Pobreza, desigualdade e políticas públicas: caracterizando e problematizando a realidade brasileira. Rev. Katál 2010; 13(2):155-163.

17. Senna MCM, Monnerat GL, Schotzz V, Magalhães R. Programa Bolsa Família: nova institucionalidade no campo da política social brasileira? Rev. Katál 2007; $10(1): 86-94$.

18. Sartori E, Garcia CHM. Políticas compensatórias versus emancipatórias: desafios para implementação de programas de geração de renda às famílias em situação de risco. RAP 2012; 46(2):425-452.

19. Navarro Z. O desenvolvimento rural no Brasil: os limites do passado e os caminhos do futuro. Estudos avançados 2001; 15(43):83-100.

Artigo apresentado em 30/06/2014

Aprovado em 11/07/2014

Versão final apresentada em 15/07/2014 